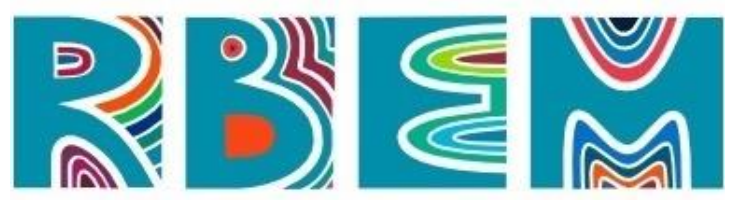

REVISTA BAIANA DE EDUCAÇÃO MATEMÁtICA

$\underline{\text { ARTIGO }}$

dol http://dx.doi.org/10.47207/rbem.v1i0.9171

\title{
Um Panorama do Ensino de Estatística em Programas de Pós-graduação em Âmbito Nacional - 2013 a 2017
}

\author{
MACHADO JÚNIOR, Arthur Gonçalves \\ Universidade Federal do Pará (UFPA). Doutor em Educação em Ciências e Matemáticas pela Universidade \\ Federal do Pará (UFPA). Docente/pesquisador do Programa de Pós-graduação em Docência em Educação em \\ Ciências e Matemática (PPGDOC/IEMCI/UFPA). ORCID: http://orcid.org/0000-0002-9933-2894. E-mail: \\ agmj@ufpa.br.
}

MARTINS, Cleuma Gonçalves Matos

Secretaria Estadual de Educação do Estado do Pará (SEDUC/PA). Especialista em Gestão Escolar pela Universidade Federal do Pará (UFPA). ORCID: http://orcid.org/0000-0003-3640-3111. E-mail: cleumamatosmm@gmail.com.

\begin{abstract}
ALMEIDA, Talita Carvalho Silva de
Universidade Federal do Pará (UFPA). Doutora em Educação Matemática pela Pontifícia Universidade Católica de São Paulo (PUC-SP). Docente da Universidade Federal do Pará, lotada no Instituto de Educação Matemática e Científica (IEMCI). ORCID: http://orcid.org/0000-0001-5206-4354. E-mail: talita_almeida@ yahoo.com.br.
\end{abstract}

Resumo: Este artigo apresenta um estudo sistematizado em programas de pós-graduação stricto senso, a nível nacional, na área do ensino da matemática. Tem como objetivo identificar como se apresenta nas pesquisas o ensino da estatística na educação básica das escolas brasileiras, bem como refletir acerca da formação inicial e continuada dos professores e quais metodologias têm sido desenvolvidas em suas práticas para possibilitar a melhoria do processo de ensino-aprendizagem em estatística. Sendo assim os descritores utilizados para a busca se configuraram como sendo: práticas investigativas no ensino da estatística e formação inicial e continuada de professores para o ensino de estatística. A pesquisa foi desenvolvida com cunho qualitativo, na modalidade bibliográfica, cujos achados são tratados a partir de uma análise interpretativa fazendo uso, como aporte teórico, dos próprios autores dos trabalhos selecionados. Após análises dos trabalhos os resultados apontam para a necessidade de intensificar pesquisas acerca do ensino de estatística com investimentos mais significativos na formação inicial e continuada dos professores para desenvolverem suas práticas no espaço escolar envolvendo o objeto de conhecimento estatístico.

Palavras-chave: Ensino. Estatística. Praticas Investigativas. Formação.

\section{An Overview of Statistics Teaching in Post-Graduate Programs at National Level - 2013 to 2017}

\begin{abstract}
This article presents a systematized study in stricto senso post-graduate programs, at national level, in mathematics education area. Its objective is to identify how the teaching of statistics in basic education of Brazilian schools is presented in research, as well as to reflect on the initial and continuing training of teachers and what methodologies have been developed in their practices to enable the improvement of the teaching-learning process in statistics. Thus, the descriptors used for the search were configured as being investigative practices in statistics teaching, and initial and continuing teacher training for the statistics teaching. The research was developed with a qualitative
\end{abstract}




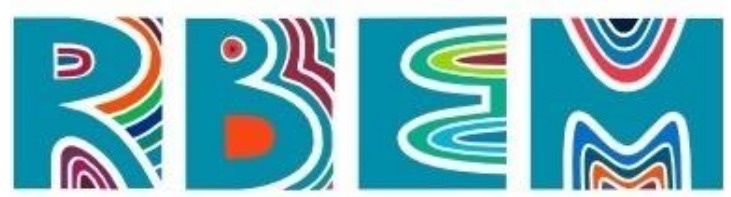

REVISTA BAIANA DE EDUCAÇÃO MATEMÁTICA

nature, in a bibliographic modality, whose findings are treated from an interpretative analysis using, as a theoretical contribution, the authors of the selected works. After analyzing the work, the results point to the need to intensify research on statistics teaching with more significant investments in the initial and continuing education of teachers to develop their practices in school space involving the object of statistical knowledge.

Keywords: Teaching. Statistic. Investigative Practices. Formation.

\title{
Una visión general de la enseñanza de la estadística en los programas de posgrado a nivel nacional - 2013 a 2017
}

\begin{abstract}
Resumen: Este artículo presenta un estudio sistemático en programas de posgrado stricto sensu, a nivel nacional, en el área de educación matemática. Tiene como objetivo identificar cómo se presenta en la investigación la enseñanza de la estadística en la educación básica en las escuelas brasileñas, así como reflexionar sobre la formación inicial y continua de los docentes y qué metodologías se han desarrollado en sus prácticas para posibilitar la mejora del proceso de enseñanza-aprendizaje. en estadística. Así, los descriptores utilizados para la búsqueda se configuraron como: prácticas investigativas en la enseñanza de la estadística y formación docente inicial y continua para la enseñanza de la estadística. La investigación se desarrolló con carácter cualitativo, en la modalidad bibliográfica, cuyos hallazgos son tratados con base en un análisis interpretativo utilizando como aporte teórico a los autores de los trabajos seleccionados. Tras el análisis del trabajo, los resultados apuntan a la necesidad de intensificar la investigación en la enseñanza de la estadística con inversiones más significativas en la formación inicial y continua de los docentes para desarrollar sus prácticas en el espacio escolar involucrando el objeto de conocimiento estadístico.

Palabras clave: Docencia. Estadística. Prácticas de investigación. Formación.
\end{abstract}

\section{Introdução}

Este artigo foi construído a partir das experiências vivenciadas como pesquisadora, no mestrado profissional ofertado pela UFPA (Universidade Federal do Pará), bem como de práticas, reflexões e discussões realizadas acerca do ensino de estatística em escolas da educação básica em que atuamos como docente no Ensino Fundamental em escolas públicas.

Ao compartilharmos com nossos pares compreensões sobre o ensino de estatística, entendemos ser necessário, a alfabetização e o letramento estatístico para tomada de decisão consciente do cidadão. Nesse sentido Ponte et al (2015) afirmam que:

[...] a Estatística constitui uma importante ferramenta para a realização de projetos e investigações em numerosos domínios, sendo usada no planejamento, na recolha e análise de dados e na realização de inferências para tomar decisões. A sua linguagem e conceitos são utilizados em cada passo do dia a dia para apoiar afirmações em domínios como a saúde, a 


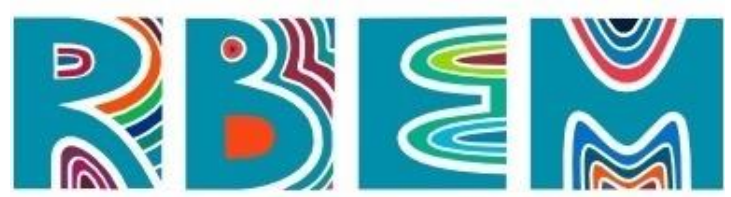

REVISTA BAIANA DE EDUCAÇÃO MATEMÁTICA

ciência, a economia e a política. Todo o cidadão precisa saber quando um argumento estatístico está ou não a ser utilizado com propriedade (PONTE, 2015, p.91).

Diante desse contexto, o objeto de conhecimento estatística passou a ser um dos focos de nossa pesquisa, bem como a busca por metodologias para possibilitar o ensino de estatística a serem desenvolvidas por professores da educação básica, e em especial os que ensinam matemática nos anos iniciais do Ensino Fundamental. Para tanto, construímos a questão de pesquisa que configura como sendo: Em que termos as práticas investigativas podem auxiliar professores com o ensino de estatística nos anos iniciais do Ensino fundamental?

Nesta perspectiva, para dar início a construção da nossa pesquisa, inicialmente fizemos um mapeamento de pesquisas brasileiras que tratam do ensino de estatística no Ensino Fundamental, com o intuito de termos aprofundamento teórico e metodológico, bem nos certificarmos acerca da pertinência da pesquisa no sentido de colaborar na efetivação de práticas docentes para o ensinar estatística no Ensino Fundamental.

Assim, ao realizarmos o mapeamento, que teve um percurso investigativo com base num estudo bibliográfico emergiram os dados para a construção deste artigo, no qual apresentamos as pesquisas encontradas, nossas análises, reflexões e conclusões sobre as pesquisas em foco. A seguir apresentamos o estudo que se configurou como sendo um panorama acerca do ensino de estatística em programas de pós-graduação no contexto brasileiro

\section{Um panorama acerca do ensino de estatística em programas de pós-graduação no contexto brasileiro.}

Neste estudo, delimitamos como foco de investigação para uma análise interpretativa de produções acadêmicas desenvolvidas entre o período de 2013 a 2017, no âmbito de programas brasileiros de pós-graduação stricto sensu credenciados na Plataforma SUCUPIRA, base de referência do Sistema Nacional de Pós-Graduação (SNPG). Os programas selecionados são da área de ensino, em cursos de mestrado profissional, acadêmico e doutorado, nas seguintes áreas de concentração: Ciências e tecnologia e educação; ensino de ciências e matemática; educação para ciências e matemática; educação e ciências e matemática; ensino de ciências; 


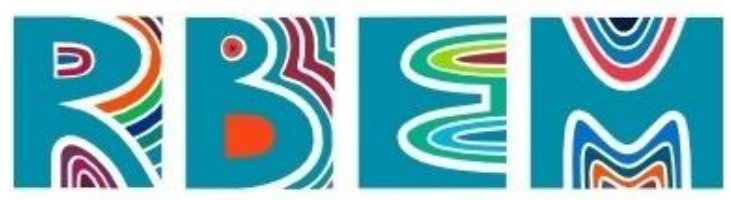

REVISTA BAIANA DE EDUCAÇÃO MATEMÁTICA

ensino de ciências e educação matemática; multiunidades em ensino de ciências e matemática; ensino de ciências, matemática e tecnologias; educação cientifica e matemática; educação matemática e tecnologia, educação científica e tecnológica; educação matemática e ensino de física; ensino e história das ciências e matemática; docência em educação em ciências e matemáticas; ensino de ciências naturais e matemática; ensino de matemática e educação em Ciências e Matemática.

Selecionamos 61 programas, nos quais buscamos identificar trabalhos que abordassem temáticas para o desenvolvimento de nossa dissertação, quais sejam: a utilização de práticas investigativas para o ensino da estatística; a formação de professores dos anos iniciais e práticas desenvolvidas para o ensino de estatística. A seguir apresentamos um quadro, com a relação das pesquisas selecionadas, no qual conta nomes dos autores, instituição e ano de conclusão.

Quadro 01: Pesquisas voltadas ao ensino de Estatística.

\begin{tabular}{|c|c|c|}
\hline $\begin{array}{l}\text { Investigação matemática: uma proposta de } \\
\text { ensino de estatística para o } 8^{\circ} \text { ano do } \\
\text { Ensino Fundamental. }\end{array}$ & $\begin{array}{l}\text { Autor(a): Scheyla } \\
\text { Heydt Réquia } \\
\text { Guerra }\end{array}$ & $\begin{array}{c}\text { UNIFRA (RS) } \\
\quad(2015)\end{array}$ \\
\hline $\begin{array}{l}\text { A Metodologia da de Problemas e o } \\
\text { Ensino de Estatística no Nono Ano do } \\
\text { Ensino Fundamental. }\end{array}$ & $\begin{array}{c}\text { Glaucia Garcia } \\
\text { Bandeira de Vargas }\end{array}$ & $\begin{array}{l}\text { UNIFRA (RS) } \\
(2013)\end{array}$ \\
\hline $\begin{array}{l}\text { Estatística: uma proposta de formação } \\
\text { continuada para professores de formação } \\
\text { Matemática do Ensino Fundamental e } \\
\text { Médio. }\end{array}$ & $\begin{array}{c}\text { Renata da Silva } \\
\text { Dessbesel }\end{array}$ & $\begin{array}{c}\text { UNIFRA (RS) } \\
(2013)\end{array}$ \\
\hline $\begin{array}{l}\text { Análise de livros didáticos conforme as } \\
\text { considerações do Programa Nacional do } \\
\text { Livro Didático: estatística } \\
\text { probabilidade. }\end{array}$ & $\begin{array}{l}\text { Danilo Messias } \\
\text { Nascimento e } \\
\text { Santos }\end{array}$ & $\begin{array}{l}\text { FUFSE (SE) } \\
(2016)\end{array}$ \\
\hline $\begin{array}{l}\text { Educação estatística sob a perspectiva } \\
\text { sociocrítica da modelagem matemática: } \\
\text { uma proposta para o Ensino Médio. }\end{array}$ & $\begin{array}{l}\text { Evânia de Oliveira } \\
\text { Pereira Lima }\end{array}$ & $\begin{array}{l}\text { IFES (ES) } \\
(2015)\end{array}$ \\
\hline $\begin{array}{l}\text { Objetos de aprendizagem na educação } \\
\text { estatística: recursos didáticos no } 1^{\circ} \text { ano do } \\
\text { Ensino Fundamental. }\end{array}$ & $\begin{array}{l}\text { Náysa Taboada da } \\
\text { Silva Alvarenga }\end{array}$ & $\begin{array}{l}\text { IFES (ES) } \\
(2016)\end{array}$ \\
\hline $\begin{array}{l}\text { Desenvolvimento de Competências } \\
\text { Estatísticas no Ensino Médio por meio da } \\
\text { modelagem Matemática: analisando as } \\
\text { diferentes representações. }\end{array}$ & Laiana Meneguelli, & $\begin{array}{l}\text { IFES (ES) } \\
(2017)\end{array}$ \\
\hline $\begin{array}{l}\text { Conhecimentos Estatísticos do Ciclo I do } \\
\text { Ensino Fundamental: Um estudo } \\
\text { diagnóstico um com professores em }\end{array}$ & Carlos Ricardo Bifi & $\begin{array}{l}\text { PUC (SP) } \\
\text { (2014) }\end{array}$ \\
\hline
\end{tabular}




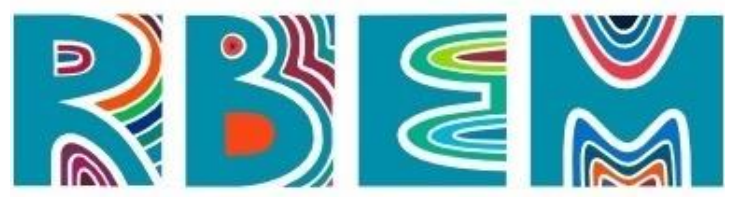

REVISTA BAIANA DE EDUCAÇÃO MATEMÁtICA

\begin{tabular}{|c|c|c|}
\hline exercício. & & \\
\hline $\begin{array}{l}\text { Aprendizagem de estatística na EJA com } \\
\text { tecnologia: uma sequência didática com } \\
\text { base nos registros de representação } \\
\text { semiótica. }\end{array}$ & Feio Reinaldo Lima & $\begin{array}{l}\text { PUC (RS) } \\
\text { (2014) }\end{array}$ \\
\hline $\begin{array}{l}\text { O Desenvolvimento Profissional de } \\
\text { Professores em Estatística: um projeto } \\
\text { Multidimensional de } \\
\text { Colaborativa. }\end{array}$ & $\begin{array}{c}\text { Leandro de } \\
\text { Oliveira Souza }\end{array}$ & $\begin{array}{l}\text { UNISUL (SP) } \\
\text { (2013) }\end{array}$ \\
\hline $\begin{array}{l}\text { A Estatística como eixo integrado no } \\
\text { Ensino de Conteúdos disciplinares na } \\
\text { promoção da interdisciplinaridade e a } \\
\text { transversalidade na educação básica. }\end{array}$ & $\begin{array}{c}\text { Marleide Campos } \\
\text { Santos Costa }\end{array}$ & $\begin{array}{l}\text { UESC (BA) } \\
(2015)\end{array}$ \\
\hline $\begin{array}{l}\text { A Formação do Usuário de Estatística } \\
\text { pelo Desenvolvimento da Literacia } \\
\text { Estatística, do Raciocínio Estatístico e do } \\
\text { Pensamento Estatístico através de } \\
\text { Atividades Exploratórias. }\end{array}$ & $\begin{array}{c}\text { Leonardo } \\
\text { Bertholdo de Assis }\end{array}$ & $\begin{array}{l}\text { UFJF (MG) } \\
\text { (2015) }\end{array}$ \\
\hline $\begin{array}{l}\text { Analisando contribuições da Teoria das } \\
\text { situações didáticas no ensino e na } \\
\text { aprendizagem da estatística e das } \\
\text { probabilidades no ensino fundamenta. }\end{array}$ & $\begin{array}{c}\text { Fabrícia Lúcia } \\
\text { Costa Ferreira da } \\
\text { Silva }\end{array}$ & $\begin{array}{l}\text { UFOP(MG) } \\
\text { (2015) }\end{array}$ \\
\hline $\begin{array}{l}\text { Concepções de Educação Estatística: } \\
\text { Narrativas de professores membros do } \\
\text { GT-12 da SBEM. }\end{array}$ & $\begin{array}{l}\text { Rodrigo Cesar } \\
\text { Cobellache }\end{array}$ & $\begin{array}{l}\text { UFPR } \\
(2017)\end{array}$ \\
\hline $\begin{array}{l}\text { O Uso de objetos de Aprendizagens de } \\
\text { Estatística em um curso de pedagogia: } \\
\text { Algumas possibilidades e potencialidades. }\end{array}$ & $\begin{array}{l}\text { Cinthia Domit } \\
\text { Zaniolo Renaux }\end{array}$ & $\begin{array}{l}\text { UFPR } \\
(2017)\end{array}$ \\
\hline $\begin{array}{l}\text { Modelagem Matemática como Ambiente } \\
\text { de Aprendizagem de Estatística na } \\
\text { Educação Básica. }\end{array}$ & $\begin{array}{c}\text { Minéia Bortole } \\
\text { Machado }\end{array}$ & $\begin{array}{l}\text { UFRGS (RS) } \\
\text { (2017) }\end{array}$ \\
\hline $\begin{array}{l}\text { O Aprendizado de Conceitos de } \\
\text { Estatística através de um Estudo sobre os } \\
\text { Óbitos dos Escravos do Rio Grande do } \\
\text { Sul no séc. XIX: Uma Experiência } \\
\text { Interdisciplinar. }\end{array}$ & $\begin{array}{c}\text { Leila Inês } \\
\text { Pagliarini De Mello }\end{array}$ & $\begin{array}{l}\text { UFRGS (RS) } \\
\text { (2017) }\end{array}$ \\
\hline $\begin{array}{l}\text { Ensino e Aprendizagem de Estatística no } \\
\text { Contexto do Ensino Médio Politécnico } \\
\text { pelo Desenvolvimento de uma Pesquisa } \\
\text { de Campo. }\end{array}$ & $\begin{array}{l}\text { Daniel Anderson } \\
\text { Müller }\end{array}$ & $\begin{array}{l}\text { UFRGS (RS) } \\
\text { (2015) }\end{array}$ \\
\hline $\begin{array}{l}\text { A Contribuição do Ensino de } \\
\text { Probabilidade e Estatística para a Prova de } \\
\text { Matemática do ENEM. }\end{array}$ & $\begin{array}{l}\text { Diego Da Silva } \\
\text { Serra }\end{array}$ & $\begin{array}{l}\text { UFRGS (RS) } \\
\quad(2015)\end{array}$ \\
\hline $\begin{array}{l}\text { O Ensino de Estatística e Matemática em } \\
\text { um } 9^{\circ} \text { ano do ensino fundamental: uma } \\
\text { abordagem interdisciplinar versando sobre } \\
\text { o tema água e desenvolvimento } \\
\text { sustentável. }\end{array}$ & $\begin{array}{l}\text { Jarbas Dionísio } \\
\text { Camargo }\end{array}$ & $\begin{array}{l}\text { UFRGS(RS) } \\
\quad(2014)\end{array}$ \\
\hline
\end{tabular}




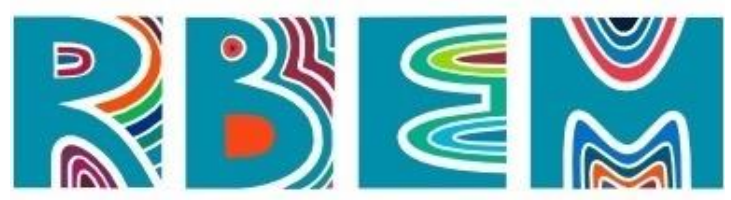

REVISTA BAIANA DE EDUCAÇÃO MATEMÁTICA

\begin{tabular}{|l|c|c|}
\hline $\begin{array}{l}\text { Proposta de Ensino de Estatística em uma } \\
\text { Turma de Nono Ano do Ensino } \\
\text { Fundamental com uso do Programa R- } \\
\text { Commander. }\end{array}$ & $\begin{array}{c}\text { Luís Henrique Pio } \\
\text { De Almeida }\end{array}$ & UFRGS(RS) \\
\hline $\begin{array}{l}\text { Os conceitos de Medidas de Tendência } \\
\text { Central e de Dispersão na Formação }\end{array}$ & $\begin{array}{c}\text { Vladimir Lira } \\
\text { Veras Xavier de } \\
\text { Estatística no Ensino Médio no Brasil e na } \\
\text { França. Abordagem Exploratória no }\end{array}$ & Andrade \\
Quadro da Teoria Antropológica do \\
$\begin{array}{l}\text { Didático e da Teoria dos Campos } \\
\text { Conceituais. }\end{array}$ & $(2013)$ \\
\hline $\begin{array}{l}\text { Saberes estatísticos mobilizados na } \\
\text { formação docente de professores dos anos } \\
\text { iniciais do ensino fundamenta. }\end{array}$ & Flvys Wagner & \\
\end{tabular}

Fonte: Construção da pesquisadora.

É possível percebermos no quadro acima a inexistência de trabalhos que tratem da temática relacionada a utilização de práticas investigativas voltadas ao ensino de estatística. Contudo alguns trabalhos apresentam discursões direcionadas a formação e concepções de professores acerca do ensino de estatística, um dos focos de interesse dessa pesquisa. Sendo assim a seguir apresentamos os trabalhos que estão relacionados a formação de professores, com olhar voltado para as pesquisas que abordam a questão dos professores dos anos iniciais do Ensino Fundamental e o ensino de estatística.

A Tese do autor Souza (2013), apresenta uma temática relacionada a educação, formação, desenvolvimento profissional e ensino em estatística, com o título: $\mathrm{O}$ DESENVOLVIMENTO PROFISSIONAL DE PROFESSORES EM ESTATÍSTICA: UM PROJETO MULTI-DIMENSIONAL DE FORMAÇÃO COLABORATIVA. A pesquisa apresenta a seguinte questão norteadora: Quais ações, em um projeto de formação contínua, contribuem para que os professores desenvolvam e mobilizem saberes no processo de ensino e de aprendizagem da Estatística?

Para responder a questão problema é delimitado o objetivo geral, como sendo: (...) compreender como, ao longo de um processo de formação colaborativo, os professores, apoiados em suas próprias experiências e nas experiências de seus colegas, podem desenvolver saberes e autonomia para investigar e melhorar continuamente sua prática e obter respostas a essas situações multiproblemáticas. Os objetivos específicos são apresentados pelo autor nos seguintes termos: 


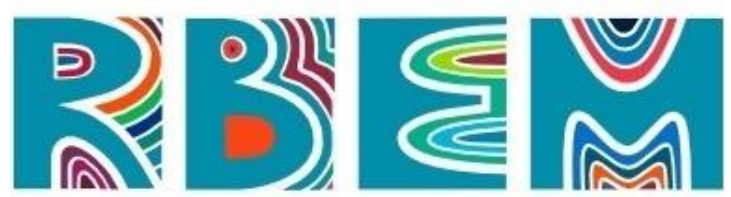

REVISTA BAIANA DE EDUCAÇÃO MATEMÁTICA

Com a nossa pesquisa, procuramos entender e refletir sobre como conduzir um processo de formação que modificasse, simultaneamente, a compreensão docente sobre o ensino de Estatística e a sua prática em sala de aula. Além disso, nossa pretensão foi entender quais são os obstáculos para os professores e os caminhos que percorre o conhecimento por eles adquirido em grupos colaborativos de formação, até chegar aos seus alunos em sala de aula. Por último, objetivamos compreender como as experiências profissionais de cada docente ao longo dos anos poderiam ajudá-los, por meio da interação em grupos, a gerenciar situações multiproblemáticas para gerar novos saberes e mudar suas abordagens de ensino (SOUZA, 2013, p.28).

Para atingir os objetivos mencionados acima, o autor opta por desenvolver uma pesquisa na modalidade da pesquisa-ação colaborativa na qual Souza (2013) "desenvolve um projeto de Formação Profissional Cíclica e Contínua de Professores em Estatística (FPCCPE), com 16 professores de Matemática dos anos finais do Ensino Fundamental, em um processo de pesquisa-ação colaborativa".

Quanto ao cenário de investigação Souza (2013), relata que inicialmente seus sujeitos foram selecionados em um grupo de aproximadamente 80 professores de Matemática da rede municipal de Ensino Fundamental da cidade de São José dos Campos. O autor chama atenção para o fato de que a pesquisa não foi construída apenas no Brasil e explicita no excerto abaixo os motivos para tal ação:

Esta pesquisa não se limitou ao cenário educacional brasileiro: minha busca para adquirir mais conhecimento no campo da Educação Estatística cruzou oceanos. Por meio de uma bolsa de estudos fornecida pela Coordenação de Aperfeiçoamento de Pessoal de Nível Superior (CAPES), estabeleci, junto com minha orientadora, Celi, uma parceria com o Departamento de Estatística da Universidade de Auckland, na Nova Zelândia(...) Durante o período de um ano, acompanhei parte do trabalho da pesquisadora Doutora Maxine Pfannkuch na formação de professores de Matemática, para que estes se familiarizassem com o novo currículo de Matemática daquele país (SOUZA, 2013, p.15).

Como instrumentos de coleta e análise de dados são utilizados na pesquisa os seguintes recursos: videogravação das oficinas de formação, entrevistas, observação do desenvolvimento dos professores no planejamento, 6 questionários, construção e aplicação 


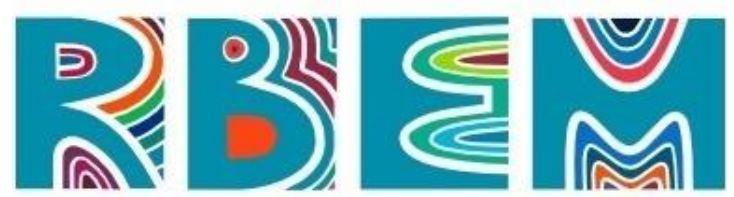

REVISTA BAIANA DE EDUCAÇÃO MATEMÁTICA

das atividades. O referido autor faz uso da pesquisa ação para o desenvolvimento de sua pesquisa e justifica nos seguintes termos:

A pesquisa ação colaborativa foi a ferramenta metodológica que entendemos ser a mais adequada para que os professores se tornassem capazes de entender as críticas como um processo de construção de conhecimento e se sentissem seguros para colaborar uns com os outros, sem medo de expor seus erros. Procuramos priorizar a reflexão do grupo sobre como desenvolver conteúdos, como construir e planejar atividades, observando e analisando quais saberes deveriam ser contemplados; e, por último, procuramos permitir que avaliassem os resultados, para que reelaborassem as suas práticas (SOUZA, 2013, p.87).

Assim Souza (2013), faz uma escolha consciente pela pesquisa ação, e afirma que:

A pesquisa ação é concebida como meio de favorecer mudanças intencionais decididas pelo pesquisador; no entanto, a mudança visada não é imposta pelo pesquisador, mas resulta de uma atividade de pesquisa na qual os atores se debruçam sobre seus próprios problemas. Depois que o processo é induzido pelos pesquisadores, em função de modalidades que eles propõem, a pesquisa sobre a situação em que atuam é efetuada pelos participantes. Barbier (2005) aponta que a ação parece prioritária nesse tipo de pesquisa, mas as consequências da ação é que permitem aos pesquisadores explorá-las com fins de pesquisa acadêmica (SOUZA, 2013, p.87).

Em relação aos aportes teóricos elencados para o desenvolvimento da pesquisa, embora o referido autor, não explicite suas escolhas, no nosso entender, demonstra, ter feito uma opção pela multireferencialidade, na seleção de autores para os diálogos e reflexões. Dessa forma os autores presentes na pesquisa são: PONTE (2011); VAZ, LOPES e SILVA (2012); PFANNKUCH e BEN-ZVI (2011); MAKAR e CONFREY (2004); COSTA e NACARATO, (2011) ; BATANERO e DIAZ (2010); BATANERO, GODINO e DELMAS (2004); GATTUSO e OTTAVIANI (2011) ; CAÑIZARES (2005) ; CARVALHO (2008); GATTUSO (2008); LOPES (1998 - 2000); SHI, HE e TAO (2009); MELETIOUMAVROTHERIS e LEE (2002); CARRILLO e CLIMENT (2011); GONÇALVES (2000). Na metodologia dialoga com autores da pesquisa ação como TRIPP (2005); BARBIER (2004); GARFIELD; FRANKLIN (2011); FIORENTINI (2009); ABDALLA (2005); THIOLLENT (1994), dentre outros. 


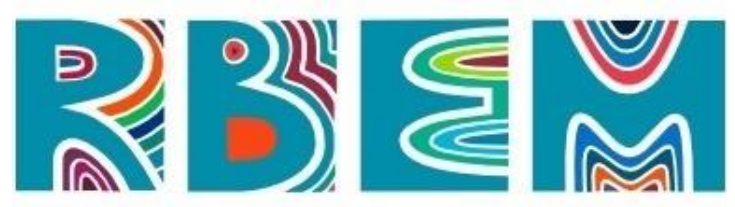

REVISTA BAIANA DE EDUCAÇÃO MATEMÁTICA

Nestes termos, ao finalizar a pesquisa Souza (2013) apresenta como contributos as seguintes considerações.

Pudemos constatar que algumas ações no processo de formação docente são essenciais: 1) o planejamento de uma atividade própria, com colaboração; 2) a realização de diferentes experimentos; 3) a utilização de recursos tecnológicos; 4) o aprimoramento das percepções sobre a diferença entre o fazer matemático e o fazer estatístico; 5) a análise sobre possibilidades e medidas de chance; 6) a conscientização sobre as etapas de investigação estatística; 7) a análise compartilhada dos resultados obtidos; 8) a inserção de leituras durante os encontros; e 9) o aprimoramento do conhecimento de conteúdo estatístico (SOUZA, 2013, p.149).

Quanto as abordagens em relação ao ensino de estatística no ensino fundamental o referido autor conclui que:

As abordagens tradicionais de ensino de Estatística e Probabilidade ainda predominam nas escolas. A reprodução das abordagens experimentadas pelo professor ao longo da formação docente pode ser vista na sua prática; por isso, é importante continuar formando o professor em serviço (SOUZA, 2013, p.149).

O autor relata ainda, que a sua intervenção teve mérito apesar das limitações relacionadas ao tempo de duração da pesquisa, neste sentido Souza (2013), salienta que "Entendemos que a formação docente não pode ter prazo determinado para acabar: ela deve ser contínua e iniciar-se a partir da prática e da necessidade dos professores. Em relação ao design de formação colaborativa, proposto para ser desenvolvido no decorrer da pesquisa, Souza (2013) fala que:

Até o final do projeto de pesquisa, nove professores mostraram ter superado as suas dificuldades de planejar a própria atividade e, para esse resultado, foram pontos fundamentais a colaboração, os desafios colocados pelos pesquisadores e a apropriação de saberes de outras pessoas do grupo. Seis desses nove professores, que realmente implementaram uma atividade desenvolvida por eles, mostraram que são capazes de mudar as abordagens de ensino da Estatística por meio de aulas investigativas. Descobriram recursos que até então não tinham sido utilizados em suas escolas; adaptaram as atividades para ensinar novos conteúdos para as turmas nas quais lecionavam; e criaram um estilo de ensino próprio por meio da autoavaliação do processo (SOUZA, 2013, p.151-152). 


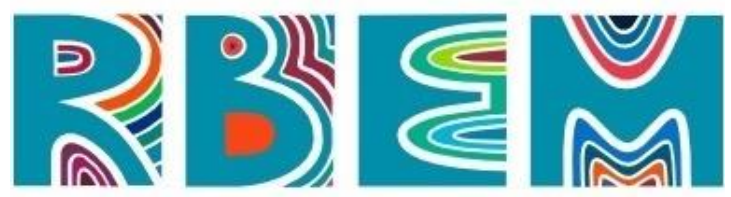

REVISTA BAIANA DE EDUCAÇÃO MATEMÁTICA

Diante do quadro exposto acima, o autor conclui ao finalizar sua pesquisa, que ainda se faz necessário o desenvolvimento de futuras pesquisas no campo da formação de professores em educação estatística, com as quais possam contribuir para compreensão por parte dos professores acerca do pensamento estatístico e matemático, bem como o desenvolvimento de práticas no que tange ao trabalho colaborativo para possibilitar a melhoria do processor ensino/aprendizagem em relação aos conhecimentos estatísticos.

Outra pesquisa relacionada a formação de professores na qual focamos nosso olhar, diz respeito a tese de Bifi (2014), a qual investiga a prática e formação continuada de professores polivalentes na área da Estatística, intitulada: CONHECIMENTOS ESTATÍSTICOS NO CICLO I DO ENSINO FUNDAMENTAL: UM ESTUDO DIAGNÓSTICO COM PROFESSORES EM EXERCÍCIO. A referida pesquisa apresenta a seguinte questão norteadora: Que conhecimentos estatísticos - didáticos e específicos - são mobilizados em situação de concepção e gestão de aula por um grupo de professores em suas práticas docentes?

Para responder à questão explicitada acima o autor construiu o objetivo de: Diagnosticar o tipo de funcionamento dos conhecimentos didáticos e matemáticos por meio da observação de atividades relacionadas à prática de um grupo de professores do Ciclo Ido 10 Ensino Fundamental. Assim sendo o autor, buscou identificar elementos que sinalizassem a percepção desses professores sobre seus conhecimentos em Estatística, Probabilidade e Combinatória, relativos ao nível de escolaridade no qual esses docentes estavam em exercício.

Quanto a metodologia adotada na pesquisa trata-se da modalidade, pesquisa - ação, com um cunho qualitativo na qual Bifi (2014) ancora-se nas ideias de Ponte (2006), entre outros. O grupo-sujeito da pesquisa compõe-se de nove professoras de Ciclo I do Ensino Fundamental de uma escola pública, com graduação em pedagogia.

Em relação aos instrumentos utilizados para coleta de dados e o percusso metodologico, conseguimos inferir apartir da leitura, que os dados da pesquisa foram coletados no período de 2010 a 2013. Sendo que o percurso metodológico foi desenvolvido em três etapas, com os seguintes procedimentos metodológicos: observação das reuniões em horário de trabalho pedagógico Coletivo (HTPC); observação da prática das professoras durante as aulas que tratavam de conteúdo do bloco 'Tratamento da informação' e, por fim, 


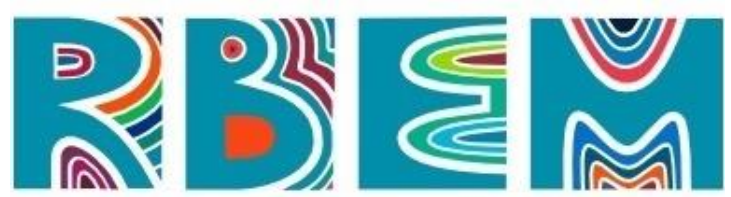

REVISTA BAIANA DE EDUCAÇÃO MATEMÁTICA

entrevistas. As duas primeiras etapas nortearam a construção de um conjunto de atividades que serviu de base para as entrevistas.

percebemos, que os autores utilizados como referência para sustentar a pesquisa foram: ERICKSON (1986); BOGDAN E BIKLEN (1994); ROBERT (1998); DEBORA BALL (1987); YIN (2003); SHULMAN (1999); BALL (2008); GAL (2002); WATSON (1997); KADER E PERRY (2006); RUMSEY (2002); GATUSSO (2006) GARFIELD E CHANCE(2004); VIALI (2008); ROBERT (1998); SHULMAN (1987); GEDDIS (1993); GUDMUNDSDOTTIR E SHULMAN, (1987); VAN DRIEL, et al. (2002); HILL, BALL E SCHILLING (2008), HILL, BALL e SCHILLING (2008); VACE; BRIGHT (1999); POLYA (2003); VIEIRA (1997); LOPES (2003); CAÑIZARES, BATANERO, SERRANO e ORTIZ (1999); GREEN (1983); COUTINHO, ALMOULOUD e SILVA,(2009) entre outros.

E mais, que após analisar os dados, Bifi (2014) chama a nossa atenção para a necessidade de criação de grupos colaborativos de trabalho coletivo na escola e do investimento em formações ou assessorias não limitadas ao HTPC, que permitam ao professor autonomia, visando a construção de conhecimentos didáticos e específicos relacionados aos conteúdos de Estatística, Probabilidade e Combinatória. Conforme excerto abaixo

Constatamos ser necessário, paralelamente aos encontros de professores em HTPC, criar e desenvolver grupos colaborativos permanentes dentro das unidades de ensino, congregando professores com formação específica em Matemática para que, juntamente com os demais integrantes, possa-se pensar em estratégias diferenciadas de ensino e em recursos didáticos que auxiliem efetivamente o professor no uso de livros-texto e dos materiais disponíveis nas escolas (BIFI, 2014, p.134).

Em se tratando dos resultados obtidos, Bifi (2014), expõe como considerações finais que sua pesquisa não traz solução inovadora, mas que apontam reflexões necessárias para melhoria da qualidade do ensino de estatística e reitera a necessidade de um olhar mais sensível para a formação inicial e continuada de professores, com a seguinte afirmativa:

O que discutimos nesta pesquisa não se apresenta como solução inovadora para o ensino do bloco 'Tratamento da informação', mas com certeza aponta reflexões sobre os conceitos do objeto estudado constatados a partir das observações, conversas e aplicação de atividade. Os resultados dessas reflexões conduziram a um nível de complexidade importante para o trabalho com esses conceitos, reiterando a necessidade de um olhar mais 


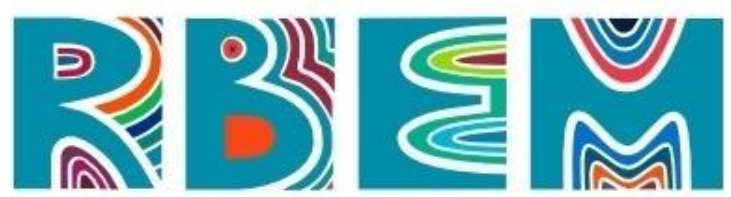

REVISTA BAIANA DE EDUCAÇÃO MATEMÁTICA

persistente para a formação inicial e continuada de professores, para o que não bastam as reflexões e discussões praticadas em HTPC (BIFI, 2014, p.114).

Pensamentos sustentados pelo autor quando afirma que:

Inferimos que um dos motivos dessa ausência do conhecimento necessário para o significado das medidas-resumo encontra-se em parte nas atividades dos livros didáticos, em que os dados se apresentam quase sempre de forma simétrica e, que na maioria das vezes, aparecem já estruturados na forma de gráficos, não permitindo uma manipulação dos dados, por exemplo, em rol. Não queremos culpar o livro didático, mas sim sugerir que a formação inicial e continuada recebida seja persistente, como já exposto. Sabemos que o papel do livro é dar apoio didático, mas percebemos que os professores os utilizam como ferramentas de formação continuada, nos termos de Lajolo (1996). Seria necessária uma ação que instrumentalizasse o professor para complementar os elementos faltantes nos livros didáticos, visando a aprendizagem dos alunos e o desenvolvimento do letramento estatístico e matemático destes (BIFI, 2014, p.114).

Ainda nesta direção, os resultados da pesquisa de Bifi (2014), apontam que existe enganos conceituais e procedimentais no tratamentos dos dados da informaçao, por parte do grupo de professores investigados. Diante desse contexto, o autor percebe que existem conhecimentos e modos de percepçao docentes dos problemas, os quais no seu entender, precisam ser investigados mais profundamente.

Assim, os resultados emergentes indicam um direcioanamento para a necessidade de pesquisas específicas sobre a compreensão docente e tipo de funcionamento dos conhecimentos identificados, visto que apresentaram características importantes e específicas não inteiramente descritas pelos referenciais utilizados. Bifi (2014) afirma ainda que reflexoes e análises mais aprofundadas poderão permitir que tais características inéditas dos níveis de funcionamento dos conhecimentos sejam adequadamente mapeadas para mehorar a qualidade do ensino de estatistica.

Diante do contexto acima e na prespectiva de enriquecer a discussão acerca da formação de professores para o ensino da estatística, além dos trabalhos apresentados de Sousa (2013) e Bifi (2014), direcionamos nossa atenção a dissertacao de autoria de Silva (2016).

Então percebemos que, Silva (2016), em sua dissertação, aborda temáticas 


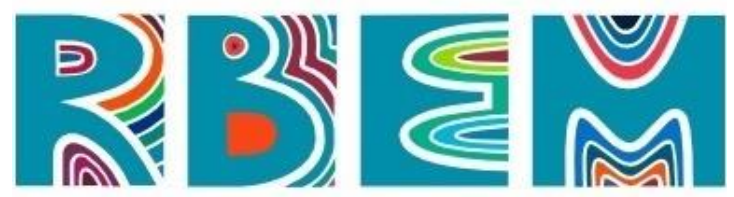

REVISTA BAIANA DE EDUCAÇÃO MATEMÁTICA

relacionadas aos: saberes docentes; saberes disciplinares; educação estatística; formação e prática pedagógica. O título da sua pesquisa é apresentado como sendo: SABERES ESTATÍSTICOS MOBILIZADOS NA FORMAÇÃO DOCENTE DE PROFESSORES DOS ANOS INICIAIS DO ENSINO FUNDAMENTAL. A questão norteadora foi construída nos seguintes termos: Que saberes disciplinares são mobilizados no campo da formação de professores para o campo da prática pedagógica relativos à Estatística?

O objetivo traçado para responder à questão problema, foi: Identificar que saberes disciplinares são mobilizados no campo da formação de professores para o campo da prática pedagógica dos anos iniciais do Ensino Fundamental relativos à Estatística. Os aportes teóricos utilizados foram: Schulman (1986), Gauthier et. al. (1998), Tardif (2002), Diaz (2010) e Garfield e Gal (1999), Lopes (1998; 2003), Cazorla (2002; 2004), Cazorla et. al. (2010), Campos (2007), Campos et. al. (2011), Guimarães (2009), dentre outros.

A pesquisa foi desenvolvida na modalidade qualitativa embasada nas concepções dos pesquisadores: Fiorentini e Lorenzato (2007); Bogdan e Biklen (1994); Fraiha-Martins (2014). O contexto para a efetivação se deu no âmbito do curso de Licenciatura Integrada em Educação, Ciências, Matemática e Linguagens, ofertado pelo Instituto de Educação Matemática e Científica (IEMCI) da Universidade Federal do Pará (UFPA) e ainda em 05 (cinco) escolas da educação básica de Belém, sendo 03 (três) da rede pública e 02 (duas) da rede privada.

Os participantes da pesquisa foram os discentes do referido curso, que desenvolveram práticas relacionadas ao ensino de estatística nas escolas selecionadas para a efetivação da pesquisa. O material de análise foi produzido no campo de formação proveniente do encontro formativo e no campo da prática pedagógica através de atividades ministradas pelos licenciados. O excerto abaixo explicita como se deu a investigação no contexto da realização da pesquisa, em relação a coleta de dados:

Campo (contexto) de pesquisa é constituído por dois contextos, a sala de aula dentro do curso de formação inicial e a sala de aula dos anos iniciais do Ensino Fundamental. Nesse sentido, o contexto da sala de aula constituía uma gama de dados que precisavam ser atentamente registrados para posterior análise. As informações foram detalhadamente coletadas e anotadas, por exemplo, a descrição do local, das pessoas e dos acontecimentos, bem como registros de atividades, fotos, desenhos e 


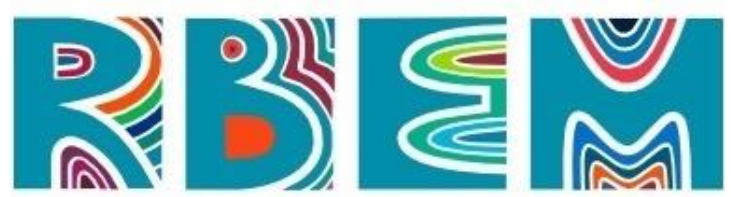

REVISTA BAIANA DE EDUCAÇÃO MATEMÁTICA

esquemas desenvolvidos pelos licenciados e pelos alunos dos anos iniciais, além de gravações em áudios e vídeos (SILVA, 2016, p.73).

Identificamos que no primeiro momento formativo da pesquisa, houve a utilização dos seguintes instrumentos para coleta de dados: Questionário contendo seis perguntas com a finalidade de colher informações acerca das concepções que os licenciados apresentavam em relação ao conhecimento de estatística; gravações em áudio e vídeo dos encontros formativos ministrados pelo pesquisador.

No segundo momento, referente as atividades de campo, o pesquisador fez uso de gravações em áudio das oficinas desenvolvidas pelos licenciados nas escolas e registros fotográficos envolvendo os licenciados e alunos durante momentos das ações desenvolvidas, bem como registros no diário de bordo.

Após finalizar as análises dos dados, Silva (2016), argumenta que, no campo da formação de professores se faz necessário o desenvolvimento de práticas, voltadas a promoção e apropriação dos saberes disciplinares relacionados a educação estatística, no intuito de promover o processo de alfabetização e letramento estatística. O referido autor propõe ainda a incursão dos licenciados no desenvolvimento de atividades pedagógicas no seio das instituições escolares com a temática de Estatística, e ressalta ainda a relevância do desenvolvimento de futuras pesquisas que tratem da relação entre saberes docente e conhecimentos estatísticos.

Para finalzar, apresentamos a pesquisa de Araújo( 2017), que traz um estudo sistemazido em programas de pós-graduação no ambito nacional entre os anos de 1994 à 2014 dos marcos históricos das pesquisas brasileiras na área de formação do professor que ensina Estatística . O títutlo escolhido para o estudo é apresentado nos termos a seguir: CONCEPÇÕES DE EDUCAÇÃO ESTATÍSTICA: NARRATIVAS DE PROFESSORES MEMBROS DO GT-12 DA SBEM.

Para desenvolver a pesquisa Araújo (2017), define a questão problema em: Investigar que concepções de Educação Estatística podem ser identificadas nas narrativas de professores pesquisadores atuantes do GT-12? Assim o principal objetivo da pesquisa se configurou como sendo: Apresentar a área de conhecimento Educação Estatística tal como é concebido por alguns pesquisadores da Educação Matemática, atuantes do GT-12 do SBEM. 


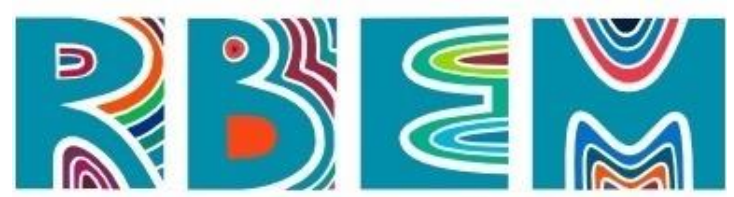

REVISTA BAIANA DE EDUCAÇÃO MATEMÁTICA

No percurso metodológico o autor utiliza as narrativas dos colaboradores entrevistados e realiza uma narrativa das narrativas, das experiências de vida dos participantes da pesquisa, tomando como referência as ideias de Garnica (2007, p.45), na qual explicita que, (...) essa análise geraria um texto ,(...) uma outra narrativa em que estariam patentes a subjetividade do intérprete e as malhas das compreensões que ele retira de quaisquer fontes por ele julgadas potenciais contribuições para a compreensão de uma dada situação ou modo de narrar.

Desta forma seguindo os procedimentos da Historia Oral, e nos trabalhos do GHOEM4 (Grupo de História Oral e Educação Matemática), Araújo (2017), realiza uma interpretação das narrativas relacionando, com a sua pesquisa desenvolvida na especialização (ARAÚJO, 2013), na qual trouxe como contributo, uma trajetória das pesquisas em Educação Estatística realizadas no Brasil até o ano de 2010.

Para construir e analisar os dados, o referido autor, desenvolveu entrevistas semiestruturadas, que foram realizadas no período da $9^{\text {a }}$ conferência Satélite da Associação Internacional de Educação Estatística (IASE), 2015. Evento que congrega especialistas, acadêmicos, profissionais e pesquisadores que debatem os avanços da Educação Estatística. Em 2015, foi realizada no Rio de Janeiro, de 22 a 24 de julho, na UNIRIO.

$\mathrm{Na}$ escolha dos participantes da pesquisa Araújo (2017), opta por pesquisadores considerados membros do GT-12, 43 professores registrados na página da Sociedade Brasileira de Educação Matemática (SBEM). Dentre estes, seleciona, seis pesquisadores, considerando critério de produção acadêmica e orientação de trabalho na área de educação estatística.

Diante dos critérios estabelecidos Araújo (2017), seleciona inicialmente baseado nos achados de Santos (2015) as professoras; Cileda de Queiroz e Silva Coutinho, pioneiras na área da pesquisa da educação estatística no Brasil e estabelece critério de rede, o qual Araújo (2017) esclarece que, ao serem convidados para participar da pesquisa, esses depoentes usualmente indicam outros depoentes - é o que se chama 'critério de rede' para a formação do núcleo de colaboradores do trabalho.

Sendo assim, pelo critério de rede, foram entrevistados os seguintes professores: Gilda Guimarães, Irene Cazorla, Ailton Paulo de Oliveira Junior, Mauren Porciúncula Moreira da Silva e Lisbeth Cordani, que desenvolvem pesquisas da região Nordeste à região Sul, sendo 


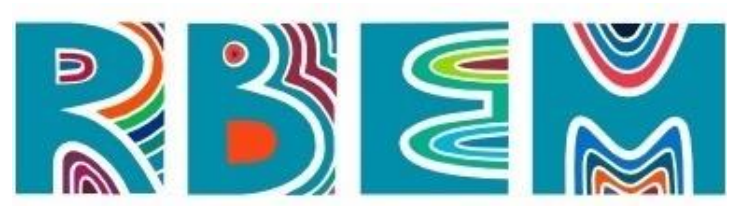

REVISTA BAIANA DE EDUCAÇÃO MATEMÁTICA

que a região norte não aparece nesse cenário e o autor não explicita o porquê. A seguir é apresentado a ilustração com um mapa que retrata o cenário.

Figura 01: Professores pesquisadores em educação estatística, entrevistados no IASE 2015 e suas respectivas localizações
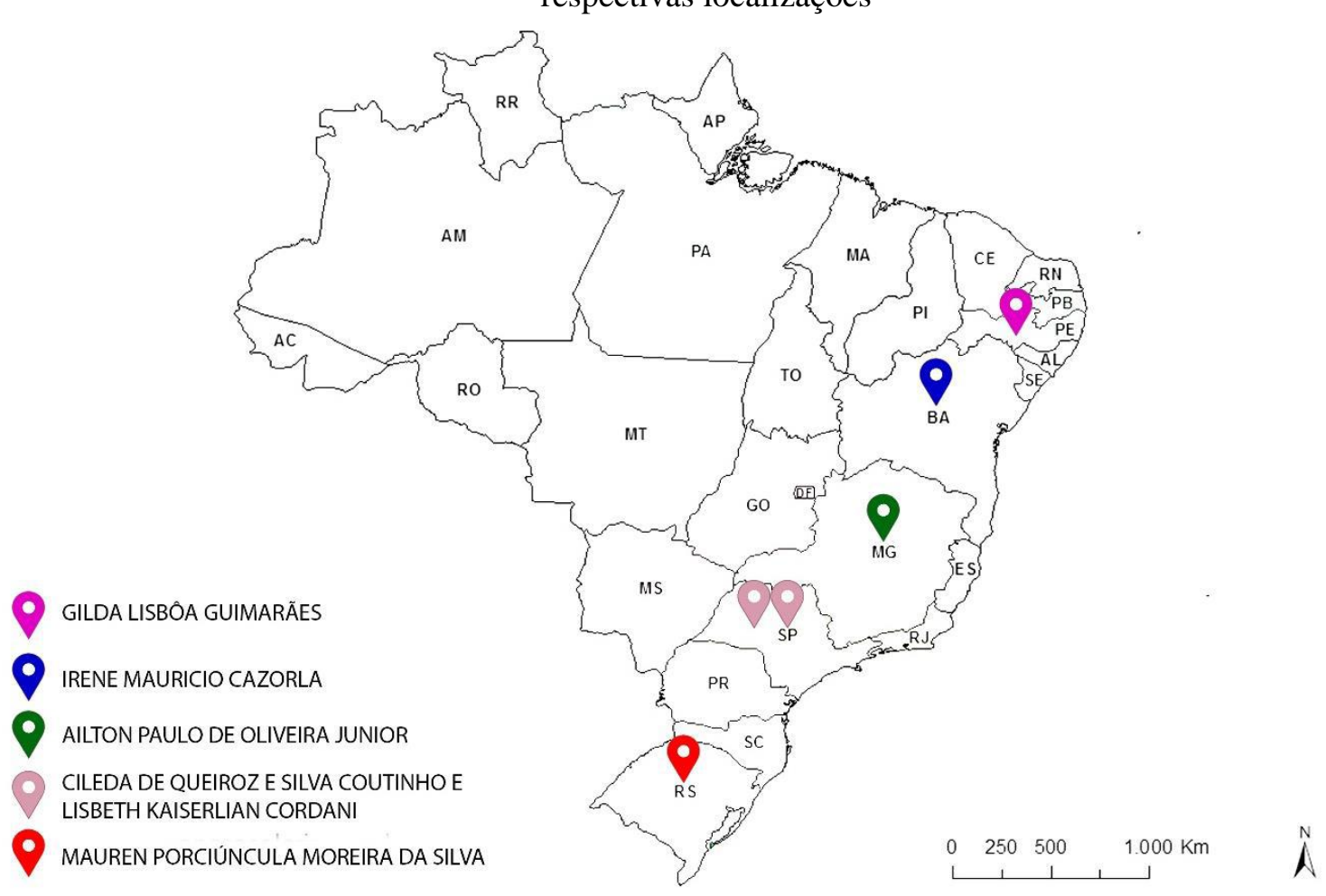

Fonte: ARAUJO, 2016, p.35

Para estabelecer o diálogo com os professores colaboradores e realizar as análises das narrativas foi adotado os seguinte aporte teórico; ALBERTI (2005); (GARNICA, 20032011); GAL (2002); SILVA BAYER et al (2009); COUTINHO (2005) MEMÓRIA (2004); BATANERO, OTTAVIANI e TRURAN (2000); CAZORLA (2006); SANTOS (2015); SANTOS (2015); CAZORLA, KATAOKA E SILVA (2010; 2015) entre outros.

Ao término da pesquisa Araújo (2017), apresenta algumas contribuições que emergiram das narrativas que ele analisou. Uma destas é a compreensão de que estatística não é matemática, mas que é preciso as ferramentas matemáticas para compreensão dos fenômenos estatísticos, neste sentido ele argumenta que: 


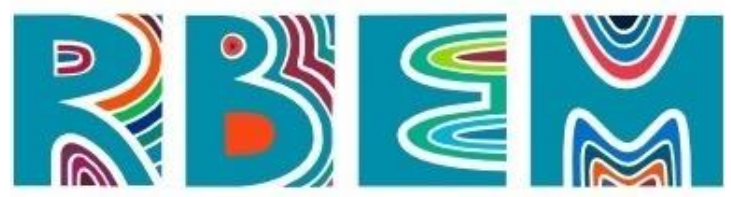

REVISTA BAIANA DE EDUCAÇÃO MATEMÁTICA

Quando se trata de estatística, Celi Lopes defende que "a estatística requer diferentes tipos de pensamento, porque dados não são somente números; são números com um contexto e, nos dados analisados, o contexto concede significado". E, com essa visão, a gente precisa desmistificar a ideia que muitos docentes têm de que estatística é matemática. Porém, precisamos de ferramentas matemáticas para compreender fenômenos estatísticos (ARAUJO,2017, p.138).

Nesta perspectiva Araújo (2017), traz para a discussão, a relação entre a educação matemática e a educação estatística. O referido autor argumenta que são duas ciências com áreas próprias de conhecimentos nos quais existem formas de pensamentos divergentes, processos mentais distintos, necessários para solução dos problemas de cada área e o fato de até mesmo pesquisadores afirmarem que a Estatística é Matemática, possivelmente foi provocado devido ao contexto histórico de como o conhecimento estatístico foi inserido na Educação Básica do Brasil.

Apesar do contexto acima, Araújo (2017), entende como ponto positivo os avanços nas pesquisas brasileiras em relação a temática do letramento estatístico e acredita que Iddo Gal foi uma referência forte para a defesa desse conceito. Ele reconhece níveis ou elementos necessários ao letramento estatístico, os quais são: habilidades de letramento; conhecimento estatístico, conhecimento matemático, conhecimento de contexto e questionamentos críticos.

Continuando sua análise o autor conclui, que ainda é preciso nos preocuparmos em letrar os professores em estatística, nos cursos de formação inicial e continuada, nos quais são necessários além do ensino das fórmulas, dominar o significado e os fundamentos da educação estatística, mas que houve avanços. Araújo (2017, p.141), afirma que (...) houve avanços no sentido de possibilitar que todo cidadão, tanto os adultos quanto as crianças, possam exercer um papel crítico, reflexivo e participativo, seja na tomada de decisões individuais ou coletivas por meio do pensamento estatístico envolvido em diversas situações do cotidiano.

Assim o referido autor, esclarece que o ambiente de realização das entrevistas evidenciou esse fato, compreende que hoje lentamente as coisas estão mudando, temos produções de pesquisas, livros e revistas, para todos os níveis de ensino, o autor afirma ainda que precisamos atingir com mais intensidade os professores da educação básica, apresentando propostas de ensino de Estatística, seja por projetos ou por processos investigativos. 


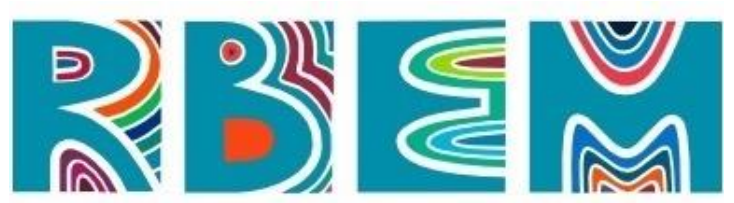

REVISTA BAIANA DE EDUCAÇÃO MATEMÁTICA

\section{Considerações finais}

Diante resultados emergentes nas pesquisas analisadas, percebemos convergência nas ideias apresentadas, pela necessidade de mais pesquisa na área de formação inicial e continuada dos professores. Apesar de que já houve avanços significativos na área de educação estatística de produção de pesquisas cientificas, ainda se faz necessário pesquisas principalmente direcionadas a práticas docentes. As pesquisas de Souza (2013); Bife (2014); Silva (2016) e Araújo (2017) apontam a necessidade do desenvolvimento de pesquisas específicas sobre a compreensão docente e tipo de funcionamento dos conhecimentos identificados para o ensino de estatística, visto que apresentaram características importantes e específicas não inteiramente descritas pelos referenciais utilizados, sobretudo envolvendo práticas de formação colaborativas que permitam ao professor autonomia, visando a construção de conhecimentos didáticos e específicos relacionados aos conteúdos de Estatística.

As pesquisas sinalizam ainda, que como a estatística é ensinada pelos matemáticos pensa-se que é matemática, isso interfere na concepção dos professores como pode ser visto nos estudo de Bife (2014), provocando práticas docentes equivocadas, o ensino matematizado martenhicica de estatística, o que não leva ao desenvolvimento do raciocínio e o pensamento estatístico necessários para se trabalhar com a incerteza e o acaso . Este problema pode ser comprovado na pesquisa de Araújo (2017) e Souza (2013).

Neste sentido como as pesquisas comprovaram, e vários pesquisadores deixaram claro, são duas ciências com áreas próprias de conhecimentos nos quais existem formas de pensamentos divergentes, processos mentais distintos, necessários para solução dos problemas de cada área mas que a estatística usa ferramentas matemáticas, na solução da sua problemática, a nosso ver, talvez esta seja uma das causas do engano e o fato de até mesmo pesquisadores afirmarem que a Estatística é Matemática, possivelmente foi provocado devido ao contexto histórico de como o conhecimento Estatístico foi inserido no currículo da educação básica do Brasil. Fato que precisa ser mais esclarecido e pode ser foco de futuras investigações.

Assim ficou claro após análises dos trabalhos e dos seus resultados, a necessidade de se intensificar pesquisas acerca do ensino de estatística e investimentos mais significativos na 


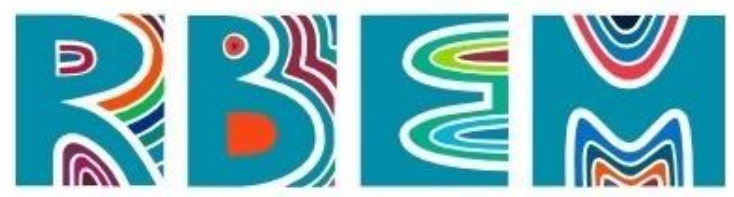

REVISTA BAIANA DE EDUCAÇĀO MATEMÁTICA

formação inicial e continuada dos professores para desenvolverem suas práticas no espaço escolar envolvendo o objeto de conhecimento estatístico.

Outro fato que as pesquisas apontam é que apesar da educação estatística ter ponto convergente com a educação matemática estes dois campos de conhecimentos possuem elementos divergentes enquanto campo de investigação.

Nesta ótica concordamos com o pensamento de Souza (2013), quando salienta para necessidade do desenvolvimento de futuras pesquisas no campo da formação de professores em educação estatística, as quais possam contribuir para compreensão por parte dos professores do pensamento estatístico e matemático, bem como o desenvolvimento de práticas no que tange ao trabalho colaborativo para possibilitar a melhoria do processor ensino/aprendizagem em relação aos conhecimentos estatísticos.

\section{Referências}

ARAUJO, E.L. Concepções de educação estatística: narrativas de professores membros do gt-12 da SBEM, Paraná - 2017.

BIFI, C. R. Conhecimentos estatísticos no Ciclo I do Ensino Fundamental: um estudo diagnóstico com professores em exercício; Pontifícia Universidade Católica de São Paulo, PUC, 2014.

MINAYO, M. C. S. O desafio da pesquisa social. In. MINAYO, M. C. S. (Org.). Pesquisa Social: teoria, método e criatividade. 34 ed. Petrópolis, RJ: Vozes, 2015.

PONTE, J. P.; BROCADO, J.; HÉLIA, O. Investigações Matemáticas na Sala de Aula. Belo Horizonte: Autêntica, 2015.

SILVA, E. W. F. Saberes estatísticos mobilizados na formação docente de professores dos anos iniciais do ensino fundamental. Universidade Federal do Pará, Instituto de Educação Matemática e Científica; Pará, 2016.

SOUZA, L. O. O Desenvolvimento Profissional de Professores em Estatística: um projeto Multidimensional de formação colaborativa. Universidade Cruzeiro do Sul, 2013.

Artigo submetido em: 26/07/2020

Artigo aceito em: 31/08/2020 